\title{
O JORNAL E A NOTÍCIA NAS AULAS DE PORTUGUÊS
}

\section{A partir do manuseio, leitura e reescrita de textos jornalísticos, alunos do ensino fundamental desenvolvem suas habilidades comunicativas}

Deparei-me, ao começar a lecionar, com uma realidade assustadora: as crianças, em sua maioria, apresentavam problemas gravíssimos de alfabetização. Problemas originados por um processo de ensino-aprendizagem tradicionalista, no qual impera a memorização de regras e conceitos com a idéia de que se aprende Língua Portuguesa a partir do ensino das categorias gramaticais.

Algo deveria ser feito, mas o quê? Também sou fruto de uma escola tradicionalista, refém de um processo decadente de ensino no Brasil. Contudo, pude perceber rapidamente a dimensão do caos. Um bom começo é reconhecer a necessidade e procurar alternativas viáveis às transformações.

Não foi do dia para a noite que me dei conta da dimensão das dificuldades. Precisei superar minha própria resistência e o desconhecimento de processos que romperiam definitivamente com essas práticas. Desde 1997 venho refletindo e pesquisando alguns procedimentos pedagógicos para a valorização da Língua Portuguesa, num trabalho que permita o uso da linguagem em situações significativas na vida dos estudantes, levando-os à apropriação da língua materna como instrumento para o sucesso na vida social, contribuindo para a formação de verdadeiros cidadãos: críticos, participativos, reflexivos, capazes de resolver problemas e tomar decisões, questionadores, afetivos, responsáveis, enfim, transformadores.

Para tanto, precisamos de professores com essas mesmas qualidades e, sobretudo, corajosos e inovadores. Professores que am-

\section{A AUTORA}

\section{Rosângela A. da Silva Grigoletto}

Professora de Português do ensino fundamental e médio em São Paulo. pliem sua visão de mundo e possam preparar o aluno a participar ativamente da sociedade, levando-o a pensar a realidade através 
das diversas formas de representação da língua, função potencialmente viável ao professor de Língua Portuguesa.

Como tentativa de alcançar os objetivos traçados no planejamento anual - oferecer ao aluno condições para compreender e desenvolver vocabulário; interpretação e produção de textos; identificar as classes gramaticais; conjugar verbos; sintaxe e muito mais, aprendizado que não ocorrera anteriormente -, optei por trabalhar os tópicos gramaticais pela morfossintaxe, o que melhorou a competência dos alunos em análise morfológica e sintática. Porém na produção de textos, momento em que os alunos deveriam colocar em prática a teoria apresentada, voltávamos à estaca zero.

Parti então para um trabalho com a reescrita de textos produzidos pelos próprios alunos. Percebi que havia despertado a preocupação deles em escrever o texto para o outro ler. Um ano de trabalho e uma vitória: meus alunos tinham consciência de que por detrás de um texto há sempre um leitor e é para ele que escrevemos. Logicamente que outros avanços se deram, mas para o assunto em pauta esse é significativo. O objetivo principal de minhas ações é desenvolver as habilidades comunicativas do educando de forma eficaz para sua formação como cidadão atuante.

Incentivada pelos temas trabalhados no Projeto de Educação Continuada - PEC (1997-1998), relativos à diversidade, intertextualidade (relação existente entre diferentes textos), coerência e coesão textual, dediquei-me aos estudos referentes à progressão textual (mecanismos de coesão) e aos gêneros do discurso em geral. Consciente de que a formação do cidadão passa pelo acesso à informação e pela sua compreensão, reconhecendo a interferência dos meios de comunicação na vida cotidiana de nossos jovens, escolhi trabalhar com os jornais da imprensa escrita e o gênero notícia.

Devo esclarecer que esta escolha se deve a alguns critérios: o jornal é um veículo formador de opiniões ideologicamente produzidas. Portanto, se meu objetivo é formar cidadãos transformadores, devo proporcionar-lhes recursos para reconhecer as marcas lingüísticas características da produção do gênero notícia ${ }^{1}$. Outra questão foi basicamente técnica, como por exemplo: a facilidade de manuseio tanto para mim quanto para os alunos, aquisição facilitada, entre outras. Assim como não existe neutralidade no ato de comunicar, minha escolha também foi diretamente influenciada pelo deslumbramento que o uso da língua escrita neste gênero exerce sobre mim. Desenvolver um projeto neste sentido seria um desafio prazeroso. 


\section{PROJETO DE TRABALHO}

Elaborei um projeto de trabalho com o gênero notícia, na disciplina Língua Portuguesa, para os alunos da sétima série do ensino fundamental da escola estadual Prof. Wilfredo Pinheiro, na Zona Leste de São Paulo. Os objetivos a alcançar foram: reconhecer as marcas linguiísticas do gênero notícia, com a finalidade de contribuir para melhorar a competência comunicativa dos alunos; promover o contato com os diferentes gêneros de textos presentes no jornal, permitindo ao educando a leitura crítica, construindo assim a consciência da cidadania.

A primeira etapa foi levar o jornal para a sala de aula e fazer com que os alunos, neste contato, identificassem: índice, ano, edição, lide, os diferentes cadernos, prestação de serviços, números de páginas (a maioria destas informações estão contidas na primeira página). $O$ manuseio do jornal como atividade inicial facilitou as demais. Cada dupla de alunos recebeu seu jornal, foram identificados com os nomes e guardados pela professora para a continuidade do projeto.

A segunda etapa consistiu em conceituar o gênero notícia e sua estrutura. Havia trabalhado textos narrativos, usando a técnica da reescrita como suporte para discussão de aspectos semânticos e gramaticais. Introduzi, então, a notícia como gênero da ordem do relatar, estabelecendo as diferenças entre as duas modalidades textuais; para tanto utilizei uma linguagem mais leve, adequando os conceitos à realidade do público-alvo. Vejamos algumas definições². Quando um cachorro morde um homem, isso não é notícia. Mas quando um homem morde um cachorro, isso é notícia. Notícia é aquilo que faz as pessoas comentarem a respeito. Notícia é somente aquilo que faz o leitor dizer: uau, que coisa! Notícia é o fato que se reveste de interesse jornalístico. $O$ interesse jornalístico depende de critérios flexíveis que variam em função do tempo, lugar, tipo de publicação etc.

Manchete é o título principal de uma notícia ou de uma reportagem. É escrita com um corpo (tamanho das letras usadas em textos, títulos e legendas) maior que os outros títulos.

Lide é o primeiro parágrafo da notícia. Deve informar quem fez o quê, a quem, quando, onde, como, por que e para quê. 
Como atividade, distribuí os jornais e pedi para os alunos que retirassem da primeira página os seguintes dados: nome do jornal, data, número e ano, edição, diretor responsável, número total de páginas, todas as manchetes, destacar a notícia principal.

Fizemos a leitura de alguns exemplares e eles foram percebendo que existe variação do número de páginas em relação ao dia da semana (por exemplo, o jornal de domingo tem uma quantidade bem maior de páginas comparado an de segunda-feira), discutimos o porquê da diferença (o jornal de domingo tem os classificados, o que acontece também nos diários de quarta-feira ou quinta-feira, dependendo da empresa).

Em relação às manchetes, sob minha orientação, foram feitas comparações entre jornais diferentes, do mesmo dia, entre os diversos títulos para noticiarem os mesmos temas. Verificamos as diferenças quanto à escolha de palavras, as expressões, o sentido figurado, o tom humorístico, os sinônimos. Os alunos realizaram a leitura das manchetes e fizemos a análise oralmente.

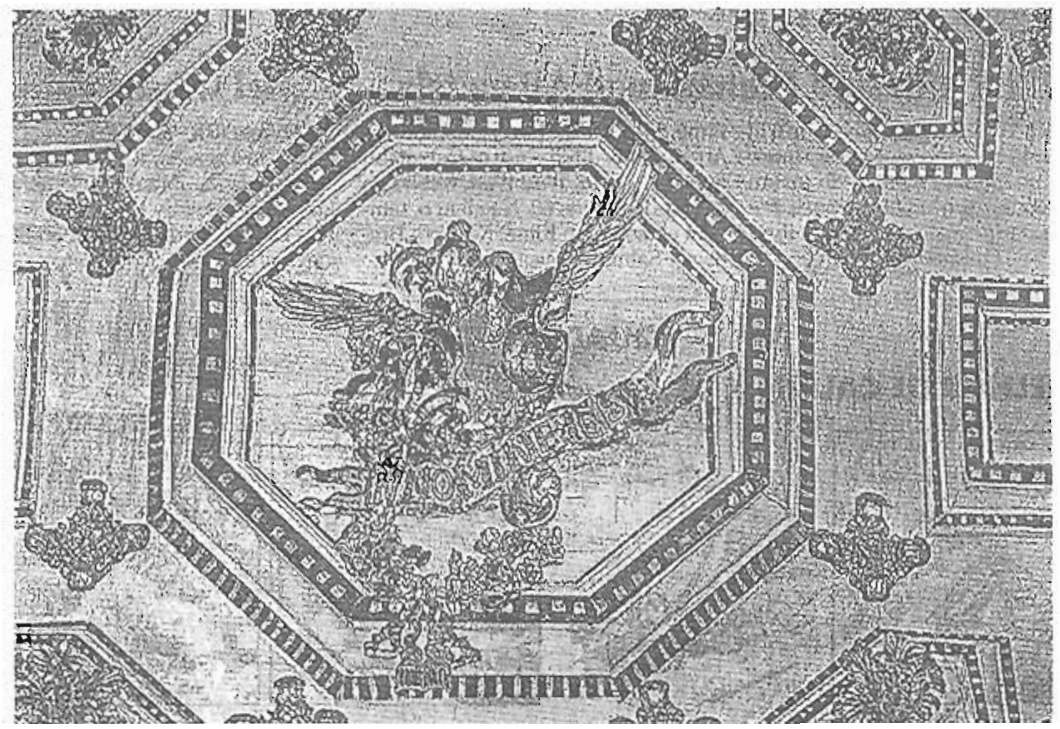

Quanto ao lide usamos o mesmo procedimento, neste caso com uma certa dificuldade, porque em uma matéria podem aparecer o lide e o sublide ${ }^{3}$. Na terceira etapa, pedi aos alunos para escolherem uma notícia, para recortarem, realizarem a colagem num papel sulfite e, após uma releitura, retirarem os elementos da notícia: o que aconteceu?; quem ou com quem?; quando se deu o fato?; onde ou em que lugar ocorreu?; e por quê?

\footnotetext{
3. Sublide é o parâgrafo seguinte ao lide. Ele contınua a dar as informaçōes mais inupoutanles para a compreensão do fato gue virou noticia. (N. Eid.)
}

As alunas da 7" sérue $B$, Aline Pereira da Silva e Julıana Andrea V. dos Santos, produzém notícia sobre restauração de basilica. 
Definimos que esta é a estrutura de uma informação e discutimos que esses são aspectos fundamentais para se desenvolver um assunto e escrever uma notícia.

$\mathrm{Na}$ quarta etapa, observamos a parte visual do jornal, especificamente a fotografia. Discutimos o efeito das imagens; se elas correspondem ao fato descrito; a disposição (formatação) geral da página. Foram levantados os seguintes pontos: a fotografia tem a intenção de chamar a atenção do leitor; elas nem sempre acompanham a manchete, o que pode ser intencional (às vezes) ou questão de espaço (diagramação).

Como atividade solicitei aos alunos que escolhessem uma fotografia do jornal e a colassem no papel sulfite (material previamente distribuído). Os jornais foram devolvidos à professora e então pedi a eles a elaboração de uma notícia a partir daquela imagem. As orientações foram as seguintes: tomar cuidado para que o texto tenha os elementos de formação da notícia, não repetir o texto original, recriar tendo como ponto de partida a imagem.

Na leitura dos trabalhos notei que todos os grupos tiveram a preocupação de adequar o texto à imagem; alguns já haviam lido a notícia vinculada à fotografia, simplesmente ignoraram a orientação da professora e reproduziram as mesmas informações; os demais atenderam às solicitações com criatividade.

Percebi que esta dinâmica agradou muito os alunos, eles ficaram empolgados com o fato de poder alterar o escrito do jornal. A partir dessa constatação, modificando um pouco o projeto original, solicitei que agissem como um redator, porque uma notícia é frequientemente reescrita - e, com o mesmo procedimento anterior (escolher, recortar e colar), reescrevessem a notícia de modo contrário ao afirmado nas manchetes, exemplo: Vereadores de Serra Negra anulam reajuste por Vereadores de Serra Negra não anulam reajuste ou Vereadores de Serra Negra aprovam reajuste.

Essa atividade rendeu muitos "nãos". Os alunos partiram das negações esquecendo-se de outros ajustes de efeito semântico. Concluí que seria um tópico a ser desenvolvido em outro projeto específico, na situação de produção de notícias.

Sentindo a empolgação da classe e aproveitando um assunto do momento - as eleições realizadas em outubro e novembro de 1998 -, fizemos entrevistas, pesquisas de opinião, os alunos assistiram ao horário eleitoral gratuito e anotaram os nomes, os partidos políticos ou coligações de todos os candidatos aos cargos de Presidente da República e Governador do Estado de São Paulo. Aproveitei o envolvimento dos alunos com o trabalho para solicitar a produção, em grupo, de uma proposta de governo para as áreas 
de: saúde, educação, segurança e uma política contra o desemprego. O grupo funcionaria como um partido político. Realizamos também a eleição de um aluno representando o candidlato ao cargo de Governador do Estado e os secretários, um para cada área.

Mesmo os alunos não tendo a idade mínima de 16 anos para o exercício do direito do voto, o objetivo dessa atividade foi a interação dos educandos com o evento das eleições, para que ganhassem consciência sobre o significado e a importância das eleições para o país, bem como a relevância da participação política do cidadão. Futuros eleitores mais exigentes e críticos requerem outros políticos: competentes, comprometidos, honestos, enfim, com todos os atributos que o homem público deve ter.

\section{A PRODUÇÃO dA NOTíca}

Finalizando o trabalho, os alunos produziram a sua notícia, com tema livre, em gxupo ou individualmente. Escolhi três delas para comentar. A primeira produzida pela aluna Maria Aparecida. Ela noticia a abertura de inscrições aos vestibulares. No enunciado o registro do sonho desses jovens: cursar o ensino superior. A notícia seguinte, produzida por urn grupo formado por quatro meninas, foi baseada nas próprias expectativas das autoras, que anteciparam a vinda do grupo Backstreet Boys ao Brasil. A terceira notícia, fruto da inventividade de três meninos que responderam imediatamente à suposta visita dos Backstreet Boys, o que para eles seria um disparate, e escreveram sobre a morte do citado grupo musical. Eles souberam trabalhar suas diferenças com criatividade e humor.

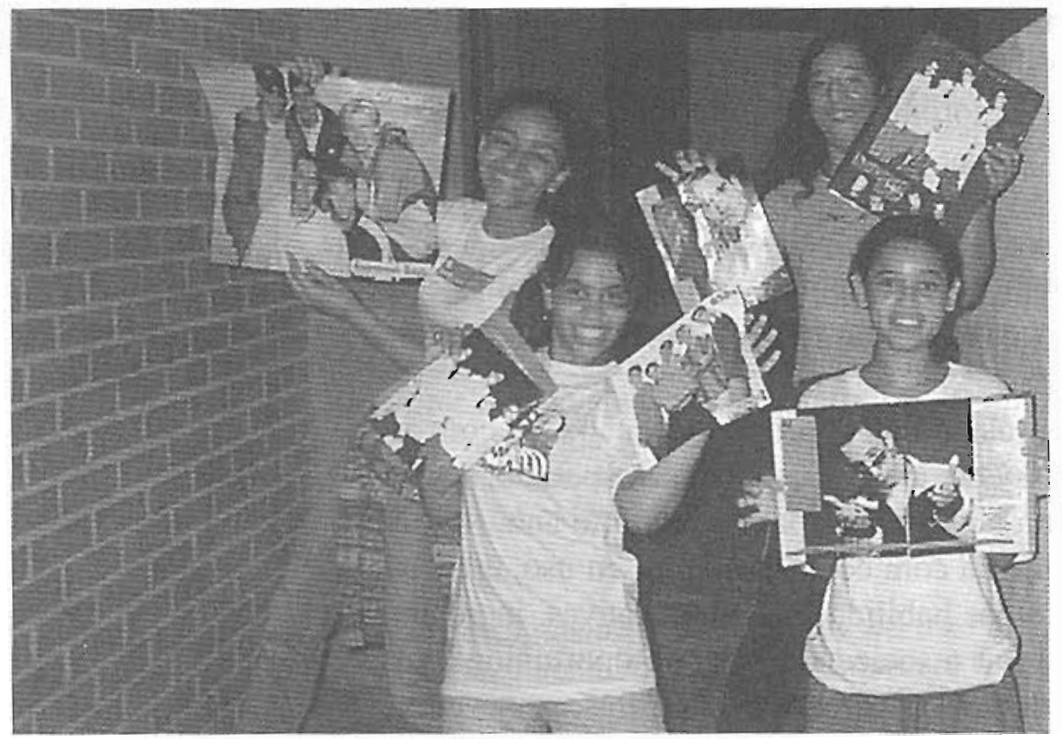

A presença do grupo de mek Backstreet Boys no Brasil é o gancho da reportagem das alunas Juliana Andrea, Aline, Daiane Juliana Cristina. 
Quando comecei a realizar esse projeto tive a intenção de sair da rotina e levar à sala de aula algo diferente, que funcionasse como uma isca para a continuidade do trabalho, ganhando o interesse dos alunos para o tema em questão e desenvolvendo um leitor crítico. Lógico que sem a pretensão de já ouvi-los discutindo sobre as consequiências das novas medidas econômicas. Mas pude, com satisfação, responder a essa expectativa no dia seguinte ao anúncio dos possíveis aumentos dos derivados de petróleo: "Professora, ontem estava assistindo ao telejornal e o repórter falou que a gasolina vai aumentar, porque o governo cortou o subsídio do petróleo, o que é subsídio?".

Ele mordeu a isca...

Uma única palavra e tenho repertório para algumas aulas, posso trabalhar a pronúncia subssídiu e não subzídio; solicitar aos alunos que consultem o dicionário e teremos o sentido denotativo, a classe gramatical, poderemos analisar o significado dentro do contexto da reportagem e, ainda, após a compreensão do vocábulo, posso debater com a classe: será que os governos dos países desenvolvidos dão subsídios à produção industrial ou para outros setores?, entre outros temas.

Para continuidade deste projeto como próximo passo, para o ano letivo de 1999, partirei da análise da notícia, a manipulação da informação e as marcas lingüísticas (escolha lexical, uso de figuras de linguagem, sensacionalismo, níveis de neutralidade). Trabalho já desenvolvido no ensino médio, no segundo ano técnico, em Contabilidade, terceiro técnico em Secretariado e terceiro semestre de Educação para jovens e adultos da rede privada. Incluirei também a progressão textual e o uso dos mecanismos de coesão, comparando os tipos de textos escritos de diversos jornais e seus estilos, textos orais da imprensa radiofônica e, finalmente, o texto televisivo e seus recursos.

Mostrar a esses jovens a importância da aplicação de quatro palavras: ler, analisar, selecionar e questionar não é tarefa fácil, mas cabe a nós professores de Língua Portuguesa fazê-lo.

Para concluir, devo relatar que o projeto foi realizado com as dificuldades de rotina mas com resultados além do esperado, sendo que na execução surgiram novas idéias para o próximo ano.

A apropriação da língua com consciência de seu uso, estimulando o desenvolvimento das habilidades comunicativas, inerentes ao ser humano, irá melhorar a sociedade, criando oportunidades a esses jovens para que possam ter perspectivas futuras, perseverem 
em seus objetivos, reconhecendo e enfrentando as dificuldades impostas pela falta de oportunidades, saindo da acomodação para a participaçāo, exercendo definitivamente a cidadania.

Devo agradecer aos meus alunos que são meu incentivo, e também aos diversos relatos e estudos de vários profissionais nos quais me inspirei e, reelaborando-os, pude começar este trabalho, tendo a grata oportunidade de relatá-los aqui.

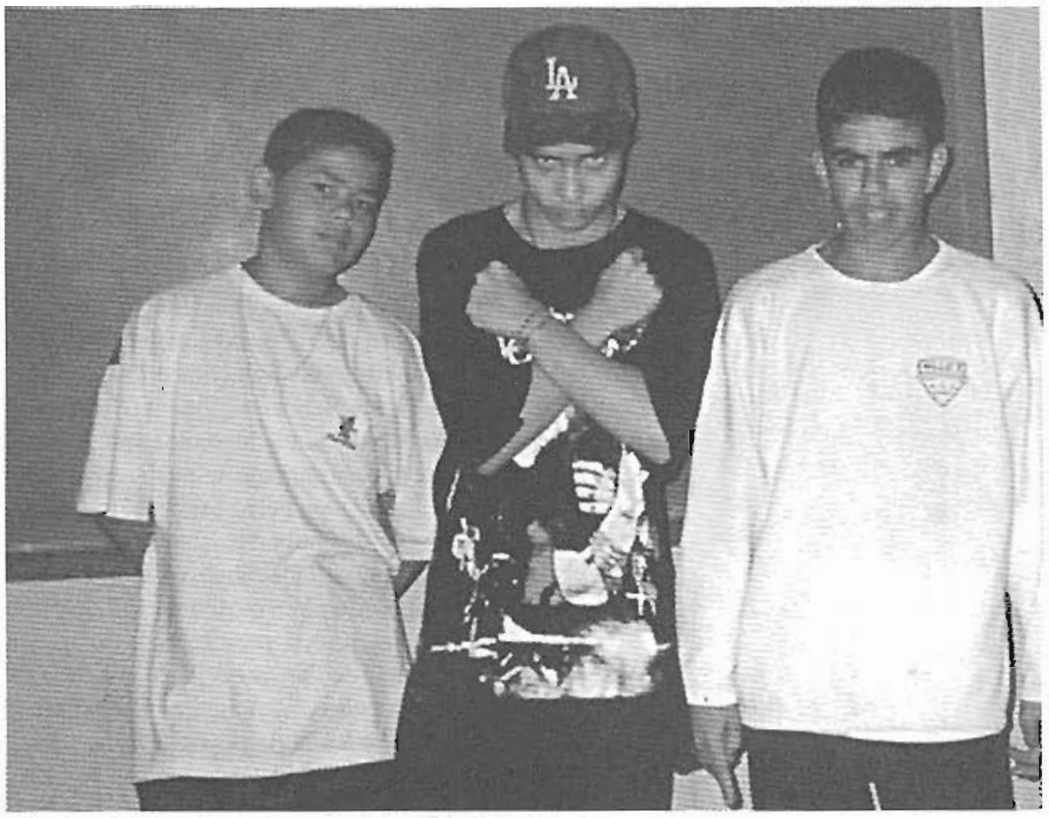

O artigo dos alunos da $7^{*}$ série $B$, Abner, Pemando e Renato contesta a qualidade musical do grupa de rock Backstreel Boys.

Resumo: Professora de Português realiza projeto de leitura e criaçāo de textos a partir do desenvolvimento das habilidades comunicativas de estudantes do ensino fundamental. Utiliza como suporte para o seu trabalho pedagógico o jornal e o gênero noticia. Aproximando os jovens dos temas importantes do país, familiariza-os com elementos textuais da notícia, bem como prepara-os para a produção desse tipo de narrativa. A partir do jornal, a professora propicia a seus alunos o desenvolvimento da capacidade de ler, selecionar, interpretar e criticar. Habilidades fundamentais para a formação de cidadāos.

Palavras-chave: Língua Portuguesa, notícia, jornal, ensino fundamental, habilidades comunicativas
Abstract: A teacher of Portuguese carries out a reading and text creation project based on the development of communicative abilities of elementary school students. This project uses the newspaper and the news genre as a support for its pedagogical work. By bringing the young people claser to important themes in the country, the project makes them familiar with the textual elements in the news, as well as prepares them to produce this type of narrative. Basing her experience on the newspaper, the teacher assists her students in their development of capabilities to read, select, interpret and criticize. These are fundamental abilities to form citizens.

Key words: Portuguese language, newspaper, elementary teaching, communicative abilities 